EPIDEMIOLOGY

\title{
Respiratory symptoms and 30 year mortality from obstructive lung disease and pneumonia
}

\author{
A Frostad, V Soyseth, T Haldorsen, A Andersen, A Gulsvik

See end of article for authors' affiliations ......................

Correspondence to: Dr A Frostad, Cancer Registry of Norway, Montebello, N-0310 Oslo, Norway: af@kreftregisteret.no

Received 20 January 2006 Accepted 23 June 2006

Published Online First

29 June 2006 term relationship between respiratory symptoms and Background: As little is known about the long term relationship between respiratory symptoms and mortality from non-malignant respiratory diseases, a respiratory symptoms and symptom load for mortality from obstructive lung disease (OLD) and pneumonia in the long term in a Norwegian population.

Methods: In 1972, 19998 persons aged 15-70 years living in Oslo were randomly selected for a respiratory survey. The response rate was $89 \%$. All were followed for 30 years. The association between cough, asthma-like symptoms, two levels of dyspnoea on exercise, a symptom score, and mortality from OLD and pneumonia were investigated separately for men and women by multivariable analyses, with adjustment for age, occupational exposure to air pollution, and smoking habits.

Results: OLD accounted for $43 \%$ and pneumonia for $50 \%$ of all deaths from respiratory causes. In men the hazard ratio for mortality from OLD varied from 4.0 (95\% confidence interval (CI) 2.4 to 6.5) for cough to 9.6 (95\% Cl 5.1 to 18.3) for severe dyspnoea, and in women from 5.1 (95\% Cl 2.3 to 11.3 ) for moderate dyspnoea to 13.0 (95\% Cl 6.0 to 28.3 ) for severe dyspnoea. The symptom score was strongly predictive of death from OLD in a dose-response manner.

Conclusions: There is a significant, positive, strong association between respiratory symptoms and 30 year mortality from OLD. The association between respiratory symptoms and mortality from pneumonia is weaker and not significant.
$\mathrm{F}$ ew population studies have focused on the predictive value of respiratory symptoms for mortality from obstructive lung disease (OLD $)^{12}$ or pneumonia, ${ }^{3}$ although these diseases are the main causes of death from non-malignant respiratory disease. ${ }^{4}$ There are known associations between respiratory symptoms and lung function ${ }^{5-7}$ and between lung function and several causes of death. ${ }^{18-10}$ The results of lung function tests depend, however, on the instruments used, the time at which the tests are conducted, and the level of training of personnel. Recording of respiratory symptoms is a cheaper and easier screening method than conducting lung function tests.

Two population based studies showed associations between cough, dyspnoea, and mortality from all respiratory diseases combined; ${ }^{11}$ one showed an association between wheezing and mortality from respiratory disease. ${ }^{9}$ Lange et al ${ }^{1}$ found that persons who reported symptoms of chronic mucus hypersecretion had a higher risk of death from OLD, and Vandentorren et al ${ }^{2}$ showed that persons reporting asthma or asthma symptoms had a higher risk of death from chronic obstructive lung disease (COPD).

Large cohorts are needed to observe a sufficient number of deaths due to cause-specific respiratory diseases. In a previous paper we found a consistent positive association between respiratory symptoms reported and all cause mortality. ${ }^{12}$ We therefore decided to extend the analyses to investigate the long term relationship between respiratory symptoms and mortality from non-malignant respiratory diseases in this large cohort. In this paper we report the predictive value of self-reported respiratory symptoms and the load of such symptoms on mortality from OLD and pneumonia over a 30 year period in a large population based sample covering nearly 500000 person-years.

\section{METHODS}

\section{Study population}

The study population was derived from a cross sectional survey conducted in Oslo in $1972 .{ }^{13}$ The sample frame was an updated list from the Central Population Register of 345630 persons aged 15-70 years living in Oslo on 1 June 1972. From this population a random sample of 19998 persons was selected to receive a postal questionnaire. During autumn 1972, 163 persons in the random sample died or emigrated and were therefore excluded from the analysis. A total of 17678 of the sample responded (response rate 89\%). The observation start date was 1 January 1973, and respondents were followed up until the date of death or emigration or until 31 December 2002, whichever occurred first (all inhabitants of Norway have a unique personal identification number that allows complete follow up until death or emigration). By 31 December 2002 the population had been followed up for 30 years, contributing a total of 489218 person-years.

The baseline characteristics of the respondents are shown in table 1.

Questionnaire and variables used in the analysis

The questionnaire used was a modification of that published by the British Medical Research Council's Committee on Research into Chronic Bronchitis in 1966. The validity of the Norwegian questions on respiratory symptoms has been examined by various methods. ${ }^{14}$ The agreement between the British and the Norwegian questionnaires varied by 85 $99 \% .^{15}$

The questionnaire contained 11 questions on respiratory symptoms which were pooled into four symptom groups (Appendix 1): cough symptoms (persons who answered "yes" to one of questions 8, 9, 10 or 11); asthma-like symptoms (those who answered "yes" to one of questions 12, 17 or 18); moderate dyspnoea (those who answered "yes" to questions 13 or 14 but not to questions 15 or 16); and severe dyspnoea (subjects who answered "yes" to questions 15 or 16). The respondents were separated into three groups on the basis of their answers to questions about smoking habits: never smokers (those who had not smoked daily for more 


\begin{tabular}{|c|c|c|c|c|c|c|}
\hline \multirow[b]{2}{*}{ Characteristic } & \multicolumn{2}{|c|}{$\begin{array}{l}\text { Total at baseline } \\
(n=17678)\end{array}$} & \multicolumn{2}{|c|}{$\begin{array}{l}\text { Deaths from OLD } \\
(n=250)\end{array}$} & \multicolumn{2}{|c|}{$\begin{array}{l}\text { Deaths from } \\
\text { pneumonia } \\
(n=293)\end{array}$} \\
\hline & $\mathrm{N}$ & $\%$ & $n$ & MR & $n$ & MR \\
\hline \multicolumn{7}{|l|}{ Sex } \\
\hline Men & 8147 & 46 & 146 & 74 & 107 & 55 \\
\hline Women & 9531 & 54 & 104 & 35 & 186 & 66 \\
\hline \multicolumn{7}{|l|}{ Respiratory symptoms* } \\
\hline None & 8696 & 49 & 36 & 16 & 143 & 64 \\
\hline $\begin{array}{l}\text { Symptom score } \\
1-3\end{array}$ & 6272 & 36 & 86 & 55 & 95 & 60 \\
\hline $4-6$ & 1966 & 11 & 62 & 137 & 30 & 66 \\
\hline$\geqslant 7$ & 712 & 4 & 66 & 511 & 23 & 178 \\
\hline \multicolumn{7}{|l|}{ Groups } \\
\hline Cough symptoms & 5732 & 32 & 175 & 129 & 106 & 78 \\
\hline Asthma-like symptoms & 6092 & 34 & 182 & 107 & 90 & 61 \\
\hline Moderate dyspnoea on exercise & 2298 & 13 & 53 & 101 & 28 & 37 \\
\hline Severe dyspnoea on exercise & 851 & 5 & 59 & 383 & 24 & 156 \\
\hline \multicolumn{7}{|l|}{ Occupational exposure† } \\
\hline Yes & 3138 & 18 & 82 & 88 & 47 & 47 \\
\hline No & 13513 & 76 & 143 & 35 & 210 & 53 \\
\hline \multicolumn{7}{|l|}{ Smoking habit } \\
\hline Never & 6567 & 37 & 24 & 14 & 117 & 69 \\
\hline Former & 2011 & 11 & 25 & 51 & 44 & 90 \\
\hline \multicolumn{7}{|l|}{ Current (g tobacco/day) } \\
\hline$<10$ & 2521 & 14 & 31 & 48 & 35 & 55 \\
\hline $10-19$ & 4399 & 25 & 107 & 99 & 59 & 55 \\
\hline$\geqslant 20$ & 1800 & 10 & 56 & 135 & 25 & 60 \\
\hline Unknown & 262 & 2 & 3 & 48 & 8 & 129 \\
\hline
\end{tabular}

than 1 year); current smokers (those who had smoked daily for more than 1 year and were still smoking at the time of the survey); the remainder were defined as former smokers. ${ }^{13}$ Smoking was measured as daily tobacco consumption calculated on the basis that one cigarette $=1 \mathrm{~g}$ tobacco. The amounts smoked by current smokers were grouped as $<10 \mathrm{~g}, 10-19 \mathrm{~g}$ and $\geqslant 20 \mathrm{~g}$ tobacco per day. For occupational exposure to air pollution, respondents were divided in two groups according to whether they answered "yes" or "no" to the question: "Have you been exposed to particles, gases or damp at your working place?"

\section{Follow up}

Notifications of death and causes of death were obtained from Statistics Norway with permission from the Data Inspectorate, the Norwegian Directorate of Health and Social Services, and the Regional Committee for Medical Research Ethics. The Norwegian death certificate is based on the international medical certificate recommended by the World Health Organization ${ }^{16}$ and physicians complete a certificate for every death. The certificate always gives the underlying cause of death and, if appropriate, contributing causes. The underlying cause is defined as the disease or injury that initiated the train of events leading to death. The contributory cause of death is often a disease that followed the underlying cause and that might have contributed to death. Norway used the 8th revision of the International Statistical Classification of Diseases, Injuries and Death (ICD) during the period 1970-85, the 9th revision up to 1995, and has used the 10th revision since 1996.

The coding and diagnosis of asthma and COPD have changed in Norway over the past 30 years. ${ }^{17}$ Many cases of COPD were previously coded as asthma when they had a similar pattern of symptoms and signs. To avoid misclassification, we pooled diagnoses related to asthma and COPD into OLD.

The analyses were based on mortality from OLD (ICD10 $\mathrm{J} 40-\mathrm{J} 47$ ) and pneumonia (ICD10 $\mathrm{J} 12-\mathrm{J} 18)^{4}$ given as the underlying cause of death. Associations between respiratory symptoms and mortality from OLD and pneumonia were also estimated when the two diagnoses were given as either the underlying or the contributing cause of death.

\section{Statistical methods}

The association between each respiratory symptom group and mortality was expressed as an adjusted hazard ratio (HR) estimated from a Cox proportional hazard regression model. ${ }^{18}$ Mortality associated with each symptom group was compared with mortality among persons who had not reported any respiratory symptoms. A symptom score ranging from 0 to 11 was defined on the basis of the sum of affirmative answers to 11 equally weighted respiratory symptom questions. The scores were then grouped as 0 (no respiratory symptoms ), $1-3,4-6$, and $\geqslant 7$ respiratory symptoms. Tests for trend were performed with symptom score and grams of tobacco smoked as continuous variables.

As mortality was more strongly associated with age than time in the study or calendar time, age was used as the underlying time scale. ${ }^{19} 20$ The proportional hazard ratio assumption of the Cox model was derived with the test of Schoenfeld's residuals on partial likelihood. ${ }^{21}$ Information about physician diagnosed OLD and coronary heart disease were considered as steps in the causal chain between respiratory symptoms and mortality, and were therefore not treated as possible confounders. The analyses were also performed after excluding those individuals with these selfreported physician diagnosed diseases.

The covariates added to the multivariable models as confounders were smoking habit and exposure to air 
Table 2 Hazard ratio (HR) with 95\% confidence interval (CI) for mortality from obstructive lung disease and pneumonia as underlying cause of death by respiratory symptom groups, symptom score and sex, adjusted for occupational exposure, smoking habits, and age in Norway, 1973-2002: separate models for each symptom group

\begin{tabular}{|c|c|c|c|c|c|c|c|c|}
\hline \multirow[b]{3}{*}{ Symptom } & \multicolumn{4}{|c|}{ Obstructive lung disease ( $n=250)$} & \multicolumn{4}{|c|}{ Pneumonia $(n=293$ ) } \\
\hline & \multicolumn{2}{|l|}{$\overline{M e n}$} & \multicolumn{2}{|l|}{ Women } & \multicolumn{2}{|l|}{$\overline{M e n}$} & \multicolumn{2}{|c|}{ Women } \\
\hline & $\overline{\mathrm{HR}}$ & $95 \% \mathrm{Cl}$ & $\overline{H R}$ & $95 \% \mathrm{Cl}$ & HR & $95 \% \mathrm{Cl}$ & $\overline{H R}$ & $95 \% \mathrm{Cl}$ \\
\hline $\begin{array}{l}\text { No respiratory symptoms } \\
\text { Symptom group }\end{array}$ & 1.0 & & 1.0 & & 1.0 & & 1.0 & \\
\hline Cough symptoms & 4.0 & 2.4 to 6.5 & 6.2 & 3.1 to 12.3 & 1.5 & 0.9 to 2.4 & 1.2 & 0.8 to 1.8 \\
\hline Asthma-like symptoms & 4.7 & 2.9 to 7.7 & 7.8 & 4.0 to 15.0 & 1.2 & 0.7 to 2.1 & 1.3 & 0.8 to 1.8 \\
\hline Moderate dyspnoea & 4.5 & 2.5 to 8.3 & 5.1 & 2.3 to 11.3 & 1.2 & 0.5 to 2.7 & 0.8 & 0.4 to 1.3 \\
\hline Severe dyspnoea & 9.6 & 5.1 to 18.3 & 13.0 & 6.0 to 28.3 & 1.5 & 0.5 to 4.6 & 1.5 & 0.9 to 2.7 \\
\hline \multicolumn{9}{|l|}{ Symptom score } \\
\hline $1-3$ & 2.3 & 1.4 to 4.0 & 3.4 & 1.7 to 6.8 & 1.5 & 1.0 to 2.4 & 0.9 & 0.6 to 1.3 \\
\hline $4-6$ & 4.1 & 2.3 to 7.5 & 9.6 & 4.5 to 20.8 & 1.5 & 0.7 to 3.2 & 1.1 & 0.6 to 1.9 \\
\hline$\geqslant 7$ & 13.6 & 7.1 to 25.9 & 21.5 & 9.4 to 49.5 & 2.0 & 0.6 to 6.2 & 3.0 & 1.5 to 6.0 \\
\hline $\mathrm{p}$ trend for symptom score & $<0.001$ & & $<0.001$ & & 0.09 & & 0.02 & \\
\hline
\end{tabular}

pollution. Separate analyses were conducted for men and women. All analyses were performed using STATA-9 (StataCorp, TX, USA).

\section{RESULTS}

Of a total of 6710 deaths in the period 1973-2002, the underlying cause recorded was respiratory disease in 582, cardiovascular disease in 2881, and cancer in 1882. Of the deaths due to respiratory disease, OLD accounted for 250 (43\%), pneumonia for 293 (50\%), and other lung diseases for $39(7 \%)$.

Among the 250 subjects in whom OLD was the underlying cause of death, no contributory cause was given in $16 \%$, cardiovascular disease was the contributory cause in 36\%, pneumonia in $20 \%$, subgroups of OLD such as bronchitis, asthma and emphysema in $16 \%$, and other diagnoses in $12 \%$. Among the 293 subjects in whom pneumonia was the underlying cause of death, no contributory cause was given in $40 \%$, senility and dementia were the contributory cause in $21 \%$, cardiovascular disease in $10 \%$, stroke sequelae in $5 \%$, and other diagnoses such as diabetes, cancer and abdominal diseases in $24 \%$. Of the 39 deaths due to other respiratory diseases, interstitial lung diseases accounted for 16, viral infections in the respiratory tract for 13, pulmonary hypertension for five, respiratory failure for two, and there were five other respiratory deaths without an exact diagnosis.

The crude mortality rate for OLD was higher for men than for women, while the opposite was true for pneumonia (table 1). When the contributory cause of death was included in the end points, the number of deaths from OLD increased by 105 to 355 and for pneumonia the number of deaths increased by 861 to 1154 .

For persons reporting any respiratory symptoms, the crude mortality rate per 100000 person-years was 99 for OLD and 69 for pneumonia. The mortality rate for OLD increased significantly with increased reporting of respiratory symptoms, while that from pneumonia showed a weaker doseresponse association (table 1). Of the 23 individuals who died from pneumonia with seven or more respiratory symptoms, 17 had physician diagnosed OLD or other respiratory disease.

The crude mortality rate for OLD was 2.5 times higher among persons exposed to dust or gases at work than in those not so exposed, while there was little difference in mortality from pneumonia. The crude mortality rate for OLD was lowest for never smokers, but a dose-response relation was found between the mortality rate and amount smoked in

Table 3 Age adjusted hazard ratio (HR) with 95\% confidence interval (CI) for mortality from obstructive lung disease and pneumonia as underlying causes of death by respiratory symptom, sex, occupational exposure, and smoking habits in Norway, 1973-2002: one model

\begin{tabular}{|c|c|c|c|c|c|c|c|c|}
\hline \multirow[b]{3}{*}{ Symptoms } & \multicolumn{4}{|c|}{ Obstructive lung disease $(n=250)$} & \multicolumn{4}{|c|}{ Pneumonia $(n=293)$} \\
\hline & \multicolumn{2}{|l|}{ Men } & \multicolumn{2}{|l|}{ Women } & \multicolumn{2}{|l|}{ Men } & \multicolumn{2}{|c|}{ Women } \\
\hline & HR & $95 \% \mathrm{Cl}$ & HR & $95 \% \mathrm{Cl}$ & HR & $95 \% \mathrm{Cl}$ & HR & $95 \% \mathrm{Cl}$ \\
\hline No respiratory symptoms & 1.0 & & 1.0 & & 1.0 & & 1.0 & \\
\hline Cough symptoms & 2.3 & 1.5 to 3.7 & 1.5 & 0.9 to 2.5 & 1.5 & 0.9 to 2.5 & 1.2 & 0.8 to 1.8 \\
\hline Asthma-like symptoms & 2.0 & 1.3 to 3.0 & 4.0 & 2.3 to 7.1 & 0.8 & 0.5 to 1.4 & 1.4 & 0.9 to 2.1 \\
\hline Moderate dyspnoea & 1.5 & 1.0 to 2.4 & 1.1 & 0.6 to 2.0 & 0.8 & 0.3 to 1.7 & 0.6 & 0.4 to 1.1 \\
\hline Severe dyspnoea & 3.3 & 2.1 to 5.3 & 2.8 & 1.6 to 4.8 & 1.2 & 0.4 to 3.5 & 1.2 & 0.7 to 2.1 \\
\hline \multicolumn{9}{|l|}{ Occupational exposure } \\
\hline No & 1.0 & & 1.0 & & 1.0 & & 1.0 & \\
\hline Yes & 1.4 & 1.1 to 2.1 & 0.7 & 0.4 to 1.3 & 0.8 & 0.5 to 1.3 & 0.9 & 0.5 to 1.5 \\
\hline \multicolumn{9}{|l|}{ Smoking } \\
\hline Never & 1.0 & & 1.0 & & 1.0 & & 1.0 & \\
\hline Former & 7.4 & 1.7 to 31.8 & 0.6 & 0.1 to 2.7 & 1.5 & 0.7 to 2.6 & 1.6 & 1.0 to 2.6 \\
\hline \multicolumn{9}{|l|}{ Current (g tobacco/day) } \\
\hline$<10$ & 7.9 & 1.8 to 35.2 & 2.6 & 1.3 to 5.2 & 1.5 & 0.7 to 3.3 & 1.1 & 0.7 to 1.8 \\
\hline $10-19$ & 13.0 & 3.1 to 53.6 & 5.2 & 2.9 to 9.4 & 1.8 & 0.9 to 3.4 & 1.2 & 0.7 to 1.9 \\
\hline$\geqslant 20$ & 19.9 & 4.8 to 83.2 & 5.9 & 2.7 to 13.0 & 2.1 & 1.0 to 4.7 & 2.7 & 1.2 to 5.7 \\
\hline $\mathrm{p}$ trend for daily smoking & $<0.001$ & & $<0.001$ & & 0.04 & & 0.08 & \\
\hline
\end{tabular}


Table 4 Hazard ratio (HR) with 95\% confidence interval (Cl) for mortality from obstructive lung disease and pneumonia as underlying causes of death by respiratory symptoms and sex, adjusted for smoking habit, occupational exposure, and age in Norway, 1973-2002. Persons who reported physician diagnosed asthma, bronchitis or emphysema are excluded. Separate models for each symptom group

\begin{tabular}{|c|c|c|c|c|c|c|c|c|}
\hline \multirow[b]{3}{*}{ Symptoms } & \multicolumn{4}{|c|}{ Obstructive lung disease $(n=112)$} & \multicolumn{4}{|c|}{ Pneumonia $(n=243)$} \\
\hline & \multicolumn{2}{|l|}{ Men } & \multicolumn{2}{|c|}{ Women } & \multicolumn{2}{|l|}{ Men } & \multicolumn{2}{|c|}{ Women } \\
\hline & HR & $95 \% \mathrm{Cl}$ & HR & $95 \% \mathrm{Cl}$ & $\mathrm{HR}$ & $95 \% \mathrm{Cl}$ & $\mathrm{HR}$ & $95 \% \mathrm{Cl}$ \\
\hline No respiratory symptoms & 1.0 & & 1.0 & & 1.0 & & 1.0 & \\
\hline Cough symptoms & 2.5 & 1.4 to 4.6 & 3.1 & 1.2 to 7.8 & 1.6 & 1.0 to 2.7 & 1.1 & 0.7 to 1.8 \\
\hline Asthma-like symptoms & 2.9 & 1.6 to 5.5 & 4.5 & 1.9 to 10.9 & 1.4 & 0.8 to 2.5 & 1.3 & 0.8 to 2.0 \\
\hline Moderate dyspnoea & 2.3 & 1.0 to 5.3 & 3.3 & 1.1 to 9.6 & 1.1 & 0.5 to 2.8 & 0.8 & 0.4 to 1.6 \\
\hline Severe dyspnoea & 4.2 & 1.5 to 11.7 & 4.6 & 1.4 to 14.7 & 1.4 & 0.3 to 5.9 & 1.2 & 0.5 to 2.5 \\
\hline
\end{tabular}

current smokers. The mortality rate due to pneumonia was highest for former smokers and did not differ by amount smoked for current smokers (table 1).

The association between each respiratory symptom group and death from OLD showed a considerable increase in the risk of mortality in both sexes: the HR was $\geqslant 4.0$ for all symptom groups and $\geqslant 10$ for those with severe dyspnoea (table 2). No significant association was found between respiratory symptom group and death from pneumonia. Mortality from OLD increased in a dose-dependent manner with the symptom score. Symptom score did not significantly increase the HR for mortality from pneumonia, except in women with $\geqslant 7$ symptoms.

The adjusted HR for mortality from OLD associated with the question "Do you have cough for 3 months or more altogether during a year?" was 7.4 (95\% CI 4.2 to 13.1) for men and 13.3 (95\% CI 6.0 to 29.4) for women, and that for mortality from pneumonia was 1.6 (95\% CI 0.7 to 3.5$)$ for men and 2.3 (95\% CI 1.2 to 4.0 ) for women. After exclusion of individuals who reported physician diagnosed asthma, bronchitis or emphysema at baseline, the association between "cough for 3 months or more ..." and mortality from OLD was 4.0 (95\% CI 2.4 to 6.5$)$ in men and 6.2 (95\% CI 3.1 to 12.3$)$ in women.

Up to 1986 all death certificates were based on clinical diagnoses. Causes of death based on autopsies were available for the period 1986-2002. During this period the proportion of clinical death diagnoses regarding OLD were $78 \%$ and $88 \%$ in the periods 1986-1995 and 1996-2003, respectively. The corresponding proportions for pneumonia deaths were $89 \%$ and $98 \%$. With regard to autopsies, mortality from OLD represented $17 \%(32 / 184)$ of the underlying causes of death and pneumonia represented 7\% (16/247). After adjustment for age, sex, occupational exposure and smoking habits, the HR for mortality from autopsy confirmed OLD varied from
3.7 (95\% CI 2.4 to 5.7 ) for cough to 6.3 (95\% CI 3.4 to 11.6 ) for severe dyspnoea. The HR for mortality from autopsy confirmed pneumonia based on symptoms, however, was not significant.

The results of the final multivariable model with all four symptom groups are shown in table 3. The association between respiratory symptoms and mortality from OLD was, as expected, weaker when all symptoms were included in the same model and adjusted for each other than when each symptom group was investigated separately. Nevertheless, for all respiratory symptom groups in men and for asthma-like symptoms and severe dyspnoea in women, the HR was still significantly increased. None of the respiratory symptoms was a significant predictor of deaths due to pneumonia.

There was a significant association between smoking habits and mortality from OLD, even after adjustment for respiratory symptoms, except for former smoking in women. The association between smoking and mortality from pneumonia was significant for men and women current smokers who smoked more than $20 \mathrm{~g}$ tobacco per day. Occupational exposure to air pollution was also a significant predictor of deaths from OLD among men when smoking and symptom groups were taken into account.

After exclusion of 3656 persons who reported physician diagnosed asthma, bronchitis or emphysema at baseline, the association between all respiratory symptoms and mortality from OLD was still significantly increased for both men and women (table 4). The HR for mortality from OLD and pneumonia did not change after further exclusion of 4146 persons who reported physician diagnosed heart failure or cardiovascular disease.

The HR for mortality from OLD decreased during follow up for all respiratory symptoms in both sexes and was still significantly increased in the third decade, except in men reporting severe dyspnoea. The HR for the third decade varied

Table 5 Hazard ratio (HR) with $95 \%$ confidence interval $(\mathrm{Cl})$ for mortality from obstructive lung disease and pneumonia as underlying or contributory causes of death, by respiratory symptoms and sex, adjusted for occupational exposure, smoking, and age in Norway, 1973-2002: separate models for each symptom group

\begin{tabular}{|c|c|c|c|c|c|c|c|c|}
\hline \multirow[b]{3}{*}{ Symptoms } & \multicolumn{4}{|c|}{ Obstructive lung disease $(n=355)$} & \multicolumn{4}{|c|}{ Pneumonia $(n=1154)$} \\
\hline & \multicolumn{2}{|l|}{ Men } & \multicolumn{2}{|c|}{ Women } & \multicolumn{2}{|l|}{ Men } & \multicolumn{2}{|c|}{ Women } \\
\hline & $\overline{H R}$ & $95 \% \mathrm{Cl}$ & HR & $95 \% \mathrm{Cl}$ & HR & $95 \% \mathrm{Cl}$ & HR & $95 \% \mathrm{Cl}$ \\
\hline No respiratory symptoms & 1.0 & & 1.0 & & 1.0 & & 1.0 & \\
\hline Cough & 4.1 & 2.9 to 5.9 & 4.2 & 2.7 to 6.5 & 1.5 & 1.2 to 1.8 & 1.2 & 1.0 to 1.5 \\
\hline Asthma-like symptoms & 4.6 & 3.2 to 6.7 & 5.0 & 3.3 to 7.6 & 1.5 & 1.3 to 1.9 & 1.2 & 0.9 to 1.5 \\
\hline Moderate dyspnoea & 5.1 & 3.3 to 7.1 & 4.0 & 2.4 to 6.6 & 1.6 & 1.2 to 2.2 & 1.2 & 0.9 to 1.5 \\
\hline Severe dyspnoea & 12.7 & 8.0 to 20.2 & 8.5 & 5.1 to 14.2 & 2.7 & 1.9 to 3.9 & 1.8 & 1.4 to 2.4 \\
\hline
\end{tabular}


from 2.5 (95\% CI 1.3 to 4.8 ) to 3.0 (95\% CI 1.2 to 7.3 ) for men and from 5.0 (95\% CI 1.7 to 14 ) to 6.7 (95\% CI 2.7 to 16) for women.

The magnitude of the associations between OLD and symptom groups did not change after OLD was added as a contributory cause (table 5). When pneumonia was added as a contributory cause of death, however, the HR for mortality from pneumonia was slightly higher for most symptom groups.

\section{DISCUSSION}

We found a significant, positive, strong predictive value of respiratory symptoms for mortality from OLD over 30 years in nearly 18000 men and women in Oslo. The relative risk for mortality decreased slightly during follow up but was still significantly increased in the third decade after recording of symptoms. The predictive value of respiratory symptoms for mortality from pneumonia was weaker and not significant. When causes contributory to the underlying cause of death were added, the association between mortality from pneumonia and respiratory symptoms changed slightly.

The large number of persons and the long follow up in our study resulted in a large number of deaths, making it possible to estimate the relative risk for mortality from OLD and pneumonia. The individuals were selected randomly and they answered the questionnaire at home, thus reducing sampling and observer bias, respectively. As there was no connection between how they answered the questionnaire and the outcome, there was no outcome-dependent bias. As the 11digit unique personal identification number used in Norway and because Statistics Norway, by law, records all deaths in the country, the estimates are not distorted by incomplete follow up.

The main source of uncertainty with regard to cause of death is the diagnosis, and physicians' reporting on the death certificates is potentially the largest source of error. In addition, the coding of diagnoses has changed, and three different ICD systems were used during the period. Uncertain associations can lead to non-differential misclassification of diagnoses and will alter the association between respiratory symptoms and mortality. ${ }^{22}$ One of the gold standards of diagnosing cause of death is, however, the autopsy. In our study the risk for mortality from OLD and pneumonia based on autopsies was similar to that for the whole cohort, thus strengthening our conclusions.

Smoking might be a strong confounder of the association between respiratory symptoms and outcome. Although we controlled for smoking habits before inclusion in the study, the prevalence of smoking in our cohort might have changed during follow up. Stavem et $a^{23}$ found that $32 \%$ of a Norwegian cohort of middle aged men had quit smoking and only 16\% had started smoking or started smoking again. In addition, the total proportion of daily smokers among Norwegian men and women decreased during the follow up period. ${ }^{4}$ Some of the respondents might have stopped smoking in response to the Norwegian Tobacco Act and to educational programmes on smoking and health. ${ }^{24}$ As a considerable proportion of the persons who smoked and reported symptoms might have had fewer symptoms after quitting during follow up, ${ }^{25}$ our analysis probably underestimates rather than overestimates the relation between symptoms and mortality.

There was an increased risk of death from OLD among smokers, which was two to three times higher among male than female current smokers. A similar trend was reported by Lange et al. ${ }^{1}$

A positive association has been reported between chronic mucus hypersecretion-that is, chronic cough with phlegm $>3$ months a year-and death from COPD in several studies, most conducted in an occupational setting, ${ }^{26-28}$ although Peto et $a 2^{27}$ found that death from COPD was not significantly related to mucus hypersecretion. In a population based study, Lange et $a l^{1}$ found a significant association between chronic mucus hypersecretion and mortality from OLD. In the Danish study the HR was adjusted for lung function. We did not have any information about lung function but we did have information about reported physician diagnosed asthma, bronchitis, or emphysema. We believe that there is an accumulation of individuals with low lung function among those with already diagnosed OLD. When excluding those individuals, we exclude the majority of subjects with low lung function. In our study, all the questions about cough were pooled into one cough symptom group. However, when we analysed reports of cough and phlegm for at least 3 months per year for at least 1 year separately with exclusion of those individuals with reported physician diagnosed asthma, bronchitis or emphysema, the HR for mortality from OLD was 1.5 times higher than in the Danish study. This could be explained by the reference populations; in the Danish study the reference population reported not having that symptom, while in our study the reference population had no respiratory symptoms at all. In line with the findings in Denmark, ${ }^{1}$ we found that the association between respiratory symptoms and mortality from OLD were similar when OLD was included as the underlying and contributory cause or only as the underlying cause of death.

With regard to asthma-like symptoms, Knuiman et al ${ }^{9}$ found that persons who reported wheezing had increased mortality from respiratory disease in general, and Carpenter et $a l^{29}$ confirmed this finding for mortality from chronic bronchitis. Vandentorren et $\mathrm{al}^{2}$ found that having asthma or asthma symptoms such as attacks of breathlessness associated with wheezing was significantly associated with mortality from COPD, with a relative risk of 3.5. In our study, asthma-like symptoms-that is, at least one of the symptoms wheezing, attacks of breathlessness or long lasting cough after a cold-resulted in a higher HR for mortality from OLD than in the study of Vandentorren et al. ${ }^{2} 9$

Our finding of a significant association between the degree of dyspnoea symptoms and death from OLD is in agreement with those of previous epidemiological surveys. ${ }^{911} 2829$ Dyspnoea on exercise is frequently a presenting symptom of both lung and heart disease. An affirmative answer to having severe dyspnoea could be an indicator of organ failure with a poor prognosis and is therefore an important predictor for mortality from OLD.

When all symptoms were adjusted for each other in the same model, the risk associated with each respiratory symptom decreased, probably because some of the symptoms are expressions of the same pathological entity in the airways. Except for cough and moderate dyspnoea in women, the risk for mortality was still significantly increased.

The crude mortality rate for death from pneumonia was higher in subjects who reported $\geqslant 7$ respiratory symptoms than in those who reported $<7$ respiratory symptoms. Among these individuals, $74 \%$ reported physician diagnosed OLD or other respiratory disease. This could indicate that OLD is underestimated as an underlying cause of death. We found a slightly increased risk of death from pneumonia associated with reports of respiratory symptoms, and the relative risk increased with increasing number of respiratory symptoms reported. Except when $\geqslant 7$ respiratory symptoms were reported in women, the association between symptoms and mortality from pneumonia was not significant, in agreement with the study by Lange et al. ${ }^{3}$ Persons who died from pneumonia had fewer respiratory symptoms at baseline and were on average 8 years older at the time of death than those who died of OLD. These observations might explain the lack 
of association between respiratory symptoms and mortality due to pneumonia.

Our study does not elucidate the mechanisms by which respiratory symptoms cause earlier death or why a single selfreport of symptoms has such a long lasting effect on mortality rates. We have nevertheless shown that common respiratory symptoms are important predictors of mortality from OLD over a period of 30 years. We believe that this information is easily obtained and should be kept in mind by physicians in clinical practice.

\section{ACKNOWLEDGEMENTS}

The authors thank Bjarte Aagnes for technical help with the data.

\section{Authors' affiliations}

A Frostad, V Soyseth, T Haldorsen, A Andersen, Cancer Registry of Norway, Montebello, N-0310 Oslo, Norway

V Soyseth, Department of Thoracic Medicine, Akershus University Hospital, N-1478 Lorenskog, Norway

A Frostad, A Gulsvik, Department of Thoracic Medicine, Institute of Medicine, University of Bergen, N-5021 Bergen, Norway

This study was financed by EXTRA funds from the Norwegian Foundation for Health and Rehabilitation.

Competing interests: none.

\section{APPENDIX 1 RESPIRATORY SYMPTOMS AND QUESTIONS DEFINING THEM}

\begin{tabular}{|c|c|c|}
\hline & Question in 1972 questionnaire & $\begin{array}{l}\text { Respiratory symptom } \\
\text { in our study }\end{array}$ \\
\hline $\begin{array}{r}8 \\
9 \\
10\end{array}$ & $\begin{array}{l}\text { Do you usually cough and clear your } \\
\text { throat in the morning? } \\
\text { Do you usually cough during the day? } \\
\text { When you cough or clear your throat, } \\
\text { do you usually bring up phlegm? } \\
\text { Do you have cough for } 3 \text { months or } \\
\text { more altogether during a year? }\end{array}$ & Cough symptoms \\
\hline $\begin{array}{l}17 \\
18\end{array}$ & $\begin{array}{l}\text { During the last } 2 \text { years, have you had } \\
\text { a cough and/or phlegm in connection } \\
\text { with a cold for more than } 3 \text { weeks? } \\
\text { Do you have attacks of breathlessness? } \\
\text { Have you ever had wheezing in your chest? }\end{array}$ & $\begin{array}{l}\text { Asthma-like } \\
\text { symptoms } \\
\text { ? }\end{array}$ \\
\hline 14 & $\begin{array}{l}\text { Are you more breathless than people of } \\
\text { your own age when walking uphill? } \\
\text { Are you breathless when you climb two } \\
\text { flights of stairs at an ordinary pace? }\end{array}$ & $\begin{array}{l}\text { Moderate dyspnoea } \\
\text { on exercise }\end{array}$ \\
\hline $\begin{array}{l}15 \\
16\end{array}$ & $\begin{array}{l}\text { Are you breathless when you walk on } \\
\text { level ground at an ordinary pace? } \\
\text { Are you breathless when at rest? }\end{array}$ & $\begin{array}{l}\text { Severe dyspnoea on } \\
\text { exercise }\end{array}$ \\
\hline
\end{tabular}

\section{REFERENCES}

1 Lange $\mathbf{P}$, Nyboe J, Appleyard $M$, et al. Relation of ventilatory impairment and of chronic mucus hypersecretion to mortality from obstructive lung disease and from all causes. Thorax 1990;45:579-85.
2 Vandentorren S, Baldi I, Annesi MI, et al. Long-term mortality among adults with or without asthma in the PAARC study. Eur Respir J 2003;21:462-7.

3 Lange $\mathbf{P}$, Vestbo J, Nyboe J. Risk factors for death and hospitalization from pneumonia. A prospective study of a general population. Eur Respir $J$ 1995;8:1694-8

4 Statistics Norway. http://statbank.ssb.no/statistikkbanken.

5 Krzyzanowski M, Camilli AE, Lebowitz MD. Relationships between pulmonary function and changes in chronic respiratory symptoms. Comparison of Tucson and Cracow longitudinal studies. Chest 1990;98:62-70.

6 Jakeways N, McKeever T, Lewis SA, et al. Relationship between FEV reduction and respiratory symptoms in the general population. Eur Respir $J$ 2003;21:658-63.

7 Sunyer J, Basagana X, Roca J, et al. Relations between respiratory symptoms and spirometric values in young adults: the European community respiratory health study. Respir Med 2004;98:1025-33.

8 Hole DJ, Watt GC, Davey-Smith G, et al. Impaired lung function and mortality risk in men and women: findings from the Renfrew and Paisley prospective population study. BMJ 1996;313:711-5.

9 Knuiman MW, James AL, Divitini ML, et al. Lung function, respiratory symptoms, and mortality: results from the Busselton Health Study. Ann Epidemiol 1999;9:297-306.

10 Mannino DM, Buist AS, Petty TL, et al. Lung function and mortality in the United States: data from the First National Health and Nutrition Examination Survey follow up study. Thorax 2003;58:388-93.

11 Rosengren A, Wilhelmsen L. Respiratory symptoms and long-term risk of death from cardiovascular disease, cancer and other causes in Swedish men. Int J Epidemiol 1998;27:962-9.

12 Frostad A, Soyseth V, Andersen A, et al. Respiratory symptoms as predictors of all-cause mortality in an urban community: a 30-year follow-up. J Intern Med 2006;259:520-9.

13 Gulsvik A. Prevalence of respiratory symptoms in the city of Oslo. Scand J Respir Dis 1979;60:275-85.

14 Gulsvik A, Bakke P, Humerfelt S, et al. Measurements of respiratory symptoms and sample size to detect a given difference between treatment groups in obstructive lung disease. Eur Respir Rev 1991;1:436-43.

15 Brogger JC, Bakke PS, Gulsvik A. Comparison of respiratory symptoms questionnaires. Int J Tuberc Lung Dis 2000;4:83-90.

16 World Health Organization. International statistical classification of diseases and related health problems: ICD-10. Geneva: World Health Organization, 1992.

17 Holten K, Tofte T. [Obstructive lung disease in a department of pulmonary medicine during the period 1979-80]. Tidsskr Nor Laegeforen 1997; 117:1585-9.

18 Cox DR. Regression models and life tables. J R Stat Soc (B) 1972;34:187-220.

19 Korn EL, Graubard BI, Midthune D. Time-to-event analysis of longitudinal follow-up of a survey: choice of the time-scale. Am J Epidemiol 1997; 145:72-80.

20 Thiebaut AC, Benichou J. Choice of time-scale in Cox's model analysis of epidemiologic cohort data: a simulation study. Stat Med 2004;23:3803-20.

21 Marubini E, Valsechi MG. Validation of the proportional hazard models. In: Analysing survival data from clinical trials and observational studies. Chichester, UK: John Wiley \& Sons, 2004:223-65.

22 Rothman KJ, Greenland S. Precision and validity in epidemiologic studies. In: Modern epidemiology. Philadelphia: Lippincott Williams \& Wilkins, 1998.

23 Stavem K, Aaser E, Sandvik L, et al. Lung function, smoking and mortality in a 26-year follow-up of healthy middle-aged males. Eur Respir J 2005;25:618-25.

24 Ronneberg A, Lund KE, Hafstad A. Lifetime smoking habits among Norwegian men and women born between 1890 and 1974. Int J Epidemiol 1994;23:267-76.

25 Eagan TM, Gulsvik A, Eide GE, et al. Remission of respiratory symptoms by smoking and occupational exposure in a cohort study. Eur Respir $J$ 2004;23:589-94.

26 Kauffmann F, Drouet D, Lellouch J, et al. Twelve years spirometric changes among Paris area workers. Int J Epidemiol 1979;8:201-12.

27 Peto $\mathbf{R}$, Speizer FE, Cochrane AL, et al. The relevance in adults of air-flow obstruction, but not of mucus hypersecretion, to mortality from chronic lung disease. Results from 20 years of prospective observation. Am Rev Respir Dis 1983;128:491-500.

28 Ebi-Kryston KL. Respiratory symptoms and pulmonary function as predictors of 10-year mortality from respiratory disease, cardiovascular disease, and all causes in the Whitehall Study. J Clin Epidemiol 1988;41:251-60.

29 Carpenter L, Beral V, Strachan D, et al. Respiratory symptoms as predictors of 27 year mortality in a representative sample of British adults. BMJ 1989;299:357-61 